\title{
É dia de fazer feira na Universidade: análise do perfil do consumidor da Polifeira
}

\author{
Suzimary Specht \\ Universidade Federal de Santa Maria - Santa Maria - Rio Grande do Sul - Brasil \\ Roni Blume \\ Universidade Federal de Santa Maria - Santa Maria - Rio Grande do Sul - Brasil \\ Marta Von Ende \\ Universidade Federal de Santa Maria - Santa Maria - Rio Grande do Sul - Brasil \\ Mylla Trisha Mello de Souza \\ Universidade Federal de Santa Maria - Santa Maria - Rio Grande do Sul - Brasil
}

\section{Resumo}

Este artigo tem como objetivo avaliar o perfil do consumidor da feira livre denominada Polifeira do Agricultor que ocorre no âmbito da Universidade Federal de Santa Maria (UFSM). A pesquisa de caráter exploratório-descritivo foi pautada em análises estatísticas com resultados quantitativos, advindos de 105 questionários estruturados aplicados com os consumidores da feira, em outubro de 2017. Como resultado observou-se, quanto ao perfil dos consumidores um número significativo de jovens (31\%), público que comumente não frequenta feiras livres. As respostas quanto à satisfação média dos consumidores, independentemente do tipo de vínculo com a UFSM, não apresentaram diferenças estatisticamente significativas em relação às características de infraestrutura da feira. Em relação à satisfação dos consumidores, a partir de quinze quesitos avaliados verificou-se que a feira corresponde às expectativas dos consumidores. O maior grau de satisfação se dá pela localização, atendimento, frescor dos produtos e confiança. O menor grau de satisfação foi atribuído à baixa variedade de produtos, seguida da restrita disponibilidade de lixeiras. Quanto à relação entre o hábito alimentar e o grau de satisfação dos consumidores verificouse que não há diferença estatisticamente significativa entre a satisfação média dos consumidores onívoros, vegetarianos e veganos. Apenas a avaliação da utilização de touca e avental mostrou-se estatisticamente diferente entre os tipos.

Palavras-chave: Feira livre. Perfil do Consumidor. Agricultores Feirantes. Polifeira.

\section{It's fair day at University: Analysis of consumer's profile from Polifeira}

\section{Abstract}

The aim of this task is to evaluate the consumer's profile when talking about the free trade fair called Farmer's Polifeira which occurs within the scope of Santa Maria Federal University 
- UFSM. The exploratory descriptive research was based on statistical analyzes with quantitative results coming from 105 structured questions which were applied in October 2017. As result was noticed, regarding the consumer's profile a significant number of youths (31\%), a public that commonly does not attend free trade fair. The answer about the average satisfaction of consumers regardless of the type of link with UFSM, did not show significant statistical difference regarding the characteristics of the free trade fair infra structure. About the consumer satisfaction from 15 questions evaluated, it was verified that the fair corresponds with the consumers expectation. The highest degree of satisfaction is about the location, way of work, products freshness and reliability. On the other side, the lowest degree of satisfaction was attributed to the low variety of products, followed by the restricted availability of waste bins. If talking about the relation between dietary habits and consumer 's satisfaction, it was found that there is no statistical significant difference between the average satisfaction of omnivores, vegetarian and vegan consumers. Only the evaluation of the use of cap and apron showed to be statistically different between the types. Keywords: Free trade fair. Consumer's profile. Market traders. Polifeira.

\section{Es el día de hacer feria en la Universidad: análisis del perfil del consumidor de la Polifeira}

\section{Resumen}

El objetivo del presente trabajo es evaluar el perfil del consumidor de la feria libre denominada Polifeira do Agricultor que se lleva a cabo dentro de la Universidad Federal de Santa Maria - UFSM. La investigación, de carácter exploratorio-descriptivo, se basó en análisis estadísticas con resultados cuantitativos, provenientes de 105 cuestionarios que fueron aplicados en octubre de 2017. Como resultados, se observó que, en relación con el perfil de los consumidores, hay un número significativo de jóvenes (31\%), público que generalmente no frecuenta ferias libres. Las respuestas referentes a la satisfacción media de los consumidores, independientemente del tipo de vínculo con la UFSM, no presentan diferencias estadísticamente significativas en relación con las características de infraestructura de la feria. La satisfacción de los consumidores fue evaluada a partir de 15 parámetros. Con estos resultados se verificó que la feria corresponde con las expectativas de los consumidores. Los ítems con mayor satisfacción fueron localización, atención, frescor de los productos y confianza. Por otra parte, la poca variedad de productos seguida de escasa disponibilidad de vertederos de basura fueron los ítems evaluados con menor grado de satisfacción. En lo referente a la relación entre el hábito alimentar y el grado de satisfacción de los consumidores, se verificó que no hay diferencia estadísticamente significativa entre la satisfacción media de los consumidores omnívoros, vegetarianos y veganos. La evaluación sobre la utilización de gorro y delantales fue el único ítem que mostró estadísticamente diferente entre los otros tipos.

Palabras clave: Feria libre. Perfil del Consumidor. Agricultores de feria. Polifeira UFSM.

\section{Introdução}

Nas feiras livres, as relações face-a-face aproximam pessoas e produtos, dinamizando circuitos curtos de comercialização que valorizam a tipicidade e produção regional e local. A criação de espaços destinados à comercialização de produtos de forma direta da unidade agrícola para o consumidor tem oportunizado novos canais de comercialização para os participantes dessas iniciativas, além de aumentar a confiança dos consumidores. A literatura tem tratado essas iniciativas como dinamizadoras de cadeias produtivas alternativas, sendo um contraponto às 
cadeias tradicionais e ao "aperto dos preços" para os produtores rurais (RENTING; MARSDEN; BANKS, 2017).

Por parte dos consumidores têm-se verificado a crescente preocupação com a qualidade dos alimentos, principalmente com os efeitos que esses têm sobre a saúde e o bem estar. No ambiente das feiras livres ocorre a circulação de um público muito diversificado que, segundo Carvalho, Rezende e Rezende (2010), tem o costume de comprar preferencialmente frutas, legumes e verduras (FLV), independente da capacidade financeira.

Por ser um público diversificado, como destacam Carvalho, Rezende e Rezende (2010), os frequentadores de feiras livres identificam este tipo de comércio como um local propício à obtenção de alimentos que proporcionam uma alimentação saudável. Além disso, também é possível encontrar produtos alimentícios diferenciados, por vezes ligados à determinada tipicidade regional como, por exemplo, a gastronomia italiana quando os feirantes são de uma região que recebeu esta colonização e trazem para a feira produtos ligados as suas tradições culinárias. Assim, a feira extrapola o seu sentido comercial e se torna também um ambiente de socialização e interação cultural (SILVA; RODRIGUES, 2011).

São estas peculiaridades que mantem as feiras livres através dos tempos, desafiando a dominação do varejo alimentar pelas poderosas e bem articuladas redes de supermercados. Este é o caso da feira de produtores familiares, denominada "Polifeira", iniciada em 2017, no campus sede da Universidade Federal de Santa Maria, Rio Grande do Sul, que é uma área pública, comumente percebida somente como um espaço restrito ao conhecimento formal, como instituição de ensino. Ao longo dos dois anos de funcionamento, a Polifeira passou a ser uma "marca" da Universidade. Destaca-se que são raros os estudos de feiras livres localizadas dentro de espaços físicos de Universidades Públicas Brasileiras, encontrados em portais de periódicos. Talvez pelo próprio ineditismo do local como canal de comercialização.

Tal constatação é que instigou a realização deste estudo, que tem como objetivo analisar o perfil dos consumidores e relacionar os hábitos alimentares dos entrevistados com as características da infraestrutura e dos produtos disponíveis para compra na Polifeira da Universidade Federal de Santa Maria, localizada na região Sul do país. Tal estudo, mesmo que embrionário, se reveste de importância, pois o entendimento do perfil e hábito de compra destes consumidores pode subsidiar a criação de canais alternativos como resposta ao desafio de proporcionar locais de comercialização para os agricultores.

Para proporcionar essa discussão, este artigo está organizado em quatro partes. Além dessa introdução, seguem algumas considerações sobre como a literatura situa o debate sobre as feiras livres, a importância do entendimento do comportamento dos consumidores e alguns apontamentos sobre canais de comercialização e mercado. Na sequência, são apresentados os procedimentos metodológicos e, posteriormente, são descritos os resultados e sua discussão. Por fim, são feitas as considerações finais do estudo.

\section{0 comportamento dos consumidores em feiras livres e a importância dos canais de comercialização e mercado.}


As feiras livres são de origem remota no Brasil. Desde a época do Império há relatos deste tipo de comércio. Atualmente, mesmo com todo o desenvolvimento dos "impérios alimentares" (PLOEG, 2008), representados em parte pela dominação das redes varejistas globais de super e hipermercados, as feiras livres se colocam como um enclave de localidade frente à globalidade do comércio varejista agroalimentar.

Ao aproximar os produtores dos consumidores, as feiras livres acabam encurtando a cadeia produtiva e possibilitam circuitos mais ágeis para 0 fornecimento e diversidade de alimentos. Tal dinâmica torna-se mais evidente quando os feirantes são agricultores familiares. Além desta peculiaridade, Godoy e Dos Anjos (2007) ressaltam que nas feiras livres o espaço é marcado por interações socioeconômicas, culturais e ambientais ampliando o sentido das relações estritamente comerciais.

Outras relações que também ocorrem nas feiras, e tem um efeito na dinâmica da família dos agricultores familiares é a promoção da empregabilidade informal. A família rural, ao executar a função de comercialização e outras atividades como transporte, embalagens ou até mesmo a troca de insumos produtivos, acabam ampliando uma intrincada rede de relações que envolvem ocupação espacial, fluxo de mercadorias e relações sociais (GODOY; DOS ANJOS, 2007).

Mas é no momento da comercialização que emergem habilidades diferenciadas dos feirantes. Além das práticas usuais ligadas a competências para produzir as mercadorias estes tem como desafio desenvolver a comunicação para a venda. Segundo Radomsky e Àvila (2018), os feirantes para promoverem a sua mercadoria devem desenvolver mecanismos de comunicação eficientes para informar os diferenciais qualitativos de seus produtos. Tal recurso é importante quando se visa criar ou manter o mercado ao gerar expectativas e simpatias com o público consumidor, ao trocar o anonimato das gôndolas do supermercado pela proximidade com os produtores/comerciantes que respondem por seus produtos nas feiras.

Além disso, também é importante investir na sociabilidade que é construída no ambiente de feira, pois esta se torna a base para as relações de confiabilidade. Nestes termos a confiabilidade é comunicada através da sociabilidade tornando-se uma estratégia que requer empenho pessoal e dedicação para a sua eficiência. $A$ compensação para este empenho é a possibilidade da geração de um diferencial competitivo ao promover a retenção e fidelização dos consumidores.

Enfatiza-se assim argumentos onde ocorrem trocas de expectativas que são de certa forma compreendidas quando se busca entender o perfil do consumidor e os fatores que influenciam no seu comportamento de compra. Como destaca Barros, Lopes e Wanderley (2007), em um mercado onde as exigências dos consumidores tem priorizado a qualidade e segurança dos alimentos, os produtores necessitam conhecer em detalhes o comportamento de seus consumidores a fim de delimitar as estratégias de mercado.

Engel, Blackwell e Miniard (2005) definem o comportamento do consumidor como sendo atividades com que as pessoas se ocupam quando obtêm, consomem ou dispõem de produtos ou serviços. Segundo Kotler e Armstrong (2014), a ação de escolha e modo de atuar dos consumidores também passa por influências de fatores culturais, sociais, econômicos, entre outros. Para Salomon (2002), o processo de 
venda é abrangente e complexo, pois lida necessariamente com a interação entre consumidores e os produtores envolvendo processos que não se resignam apenas a uma troca de um valor monetário por um bem. As interações criam expectativas que, quando atendidas de forma satisfatória, isto é, quando o bem adquirido corresponde com as expectativas e o desejo do consumidor, promovem a criação de valor.

De certa forma se observa essa criação de valor entre os consumidores e os feirantes no processo de fidelização. É no contato face a face que são estabelecidos os contratos verbais relativos às condições da garantia da qualidade dos alimentos. Assim, essa interação cria laços para além da transação comercial e os produtos tornam-se uma extensão das práticas dos agricultores feirantes, por vezes, ocorrendo até troca de saberes sobre os alimentos e seus usos. Nesse processo de socialização, a certificação da qualidade é dada pela confiança mútua entre as partes, por meio de um acordo informal, pelo qual a palavra do produtor se funde com as expectativas do consumidor. Ressalta-se também neste processo a confiança pela socialização destacada anteriormente por Radomsky e Àvila (2018).

Como podemos observar na literatura até então tratada, as feiras livres são uma forma de conectar ou reconectar o consumo e a produção. Desta forma derivam diferentes dinâmicas que formatam este canal de comercialização e interação com o mercado.

A feira como um canal de comercialização pode ser estudada como um mercado local ou territorial. Segundo Schneider (2016), os mercados locais e territoriais, dentro de uma tipologia de mercados para a agricultura familiar, estão assentados em trocas mercantis simples, sendo que estas mercadorias e produtos carregam consigo identificadores que diferenciam e valorizam a sua procedência. Segundo o autor, estes espaços de comercialização são marcados por valores como reputação, confiança, honra entre outros, que interagem no processo de compra e influenciam a tomada de decisão por parte dos consumidores. Neste tipo de mercado é comum haverem mecanismos formais ou tácitos de acreditação ou de garantia da qualidade, sendo que estes se tornam mais formais quando ocorre um distanciamento entre os produtores e consumidores.

Contudo, as formas de regulação para este mercado podem ser compostas de um mix de mecanismos. Este mix pode variar de um tipo de controle interpessoal onde é valorizada a reputação e confiança, até outros mecanismos mais formais e institucionais como os certificados e selos de procedência ou estar meramente restrita ao próprio mercado convencional quando o controle é estritamente por preços. Portanto, Schneider (2016) ressalta que o dispositivo de regulação que se estabelece nas relações comerciais em mercados locais e territoriais dependem das características dos produtores, das formas de mediação e dos objetivos que configuram as comercializações estabelecidas.

Portanto, as feiras livres têm resistido a denominação das grandes redes varejistas alimentares pelas suas dinâmicas espaciais e relacionais atreladas a especificidades deste canal de comercialização. Ao promover a aproximação dos produtores aos consumidores estes circuitos locais de comercialização promovem interações sociais diferenciadas. Nestas interações os valores não ficam restritos às questões monetárias, pois passam a fazer parte da negociação outros atributos como reputação e confiança que resguardam as transações econômicas e ampliam os laços entre os produtores e os consumidores. 


\section{Metodologia}

A pesquisa de campo teve caráter exploratório-descritivo, com análises estatísticas e resultados quantitativos, advindos da aplicação de 105 questionários estruturados, aplicados junto a consumidores da Polifeira da UFSM no mês de outubro de 2017. A pesquisa com caráter exploratório serve para realizar inferência em temáticas pouco abordadas e a análise descritiva descreve as características sobre determinada população (GIL, 2002; MALHOTRA, 2001).

O questionário foi composto de perguntas fechadas de múltipla escolha e outras abertas de caráter qualitativo. Para execução, as perguntas foram estruturadas em três partes: a primeira buscou entender o perfil socioeconômico e espacial do consumidor, a segunda procurou identificar os hábitos de consumo e a terceira avaliou as características funcionais da feira e a qualidade dos produtos.

Para as questões relacionadas à avaliação da satisfação com a feira foi utilizada uma escala tipo Likert de 5 pontos, onde o respondente se posiciona atribuindo notas que variam de 5 (muito satisfeito) a 1 (muito insatisfeito) em relação a 15 quesitos avaliados, quais sejam: localização; horário da feira; organização das bancas; atendimento dos feirantes; uso de touca e avental pelos feirantes; limpeza; disponibilidade de lixeiras; espaço de convivência; variedade de produtos; frescor dos produtos; sabor; aparência e formato do produto; preços dos produtos; produtos diferenciados; e confiança .

Os resultados do estudo foram explorados por meio de estatísticas descritivas, a fim de se ter uma primeira aproximação para a compreensão do perfil do consumidor. A estatística descritiva, enquanto ramo dentro da Estatística, consiste na etapa inicial da análise, aplicando várias técnicas para descrever e sumarizar um conjunto de dados (FREUND, 2006).

Além da análise descritiva, também foram operacionalizados testes de diferença de médias para comparar a satisfação entre grupos de consumidores. Para isso, foi utilizada a Análise de Variância (ANOVA) e o teste de Tukey para identificar a diferença entre os grupos de consumidores. As análises foram desenvolvidas com apoio do pacote estatístico SPSS 18.

\section{Resultados e Discussão}

A feira livre denominada Polifeira do Agricultor é decorrente de um projeto de extensão executado pelos integrantes do Grupo Interdisciplinar de Pesquisas Agroalimentares Georreferenciadas (GIPAG), do Colégio Politécnico da Universidade Federal de Santa Maria. A Polifeira ocorre duas vezes por semana no campus central, desde abril de 2017, no período da tarde entre as 13h30min e às 17h3omin. Na feira tem-se a participação de dezoito agricultores da região da Depressão Central - RS, que comercializam frutas, legumes, verduras, embutidos e laticínios. Cabe destacar que para participar da feira os agricultores devem se candidatar a um edital e seguir regras específicas quanto aos produtos e forma de comercialização. As principais regras são as seguintes: comercialização exclusiva de produtos oriundos das suas unidades produtivas, permissão para acompanhamento técnico contínuo dessas unidades e participação dos feirantes em cursos de capacitação. Além disso, há todo 
um empenho por parte dos coordenadores do projeto na divulgação desse canal de comercialização com investimento em marketing. As barracas e feirantes têm uma caracterização padrão, além de terem sua própria marca, como se apresenta na Figura 1, com o propósito de tornar o ambiente harmonioso e convidativo aos potenciais consumidores.

Figura 1. Imagens e Logomarca da Polifeira do Agricultor

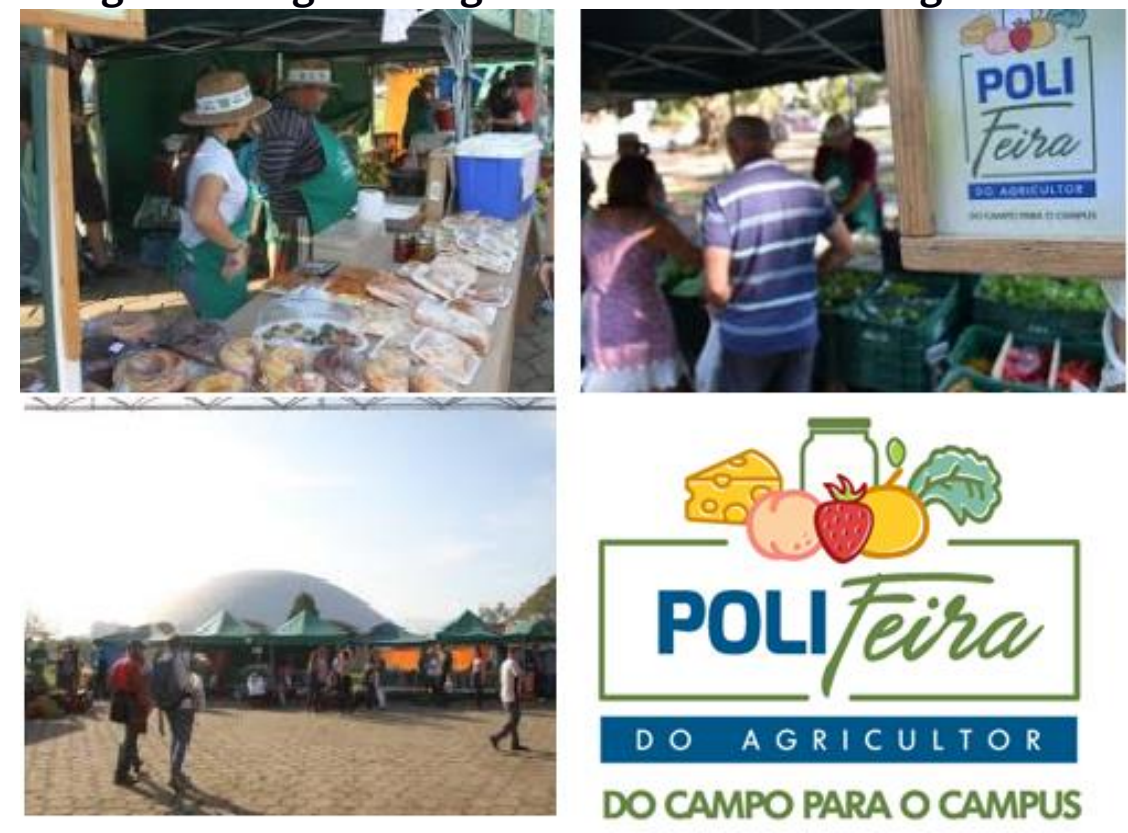

Fonte: coordenação da Polifeira.

Quanto ao perfil socioeconômico e espacial dos consumidores da Polifeira, o Quadro 1 sintetiza as principais características dos consumidores pesquisados. 
Quadro 1. Perfil socioeconômico e espacial da amostra

\begin{tabular}{|c|c|c|c|}
\hline Faixa etária da amostra & $\%$ & Gênero & $\%$ \\
\hline Até 25 anos & 30,8 & Feminino & 63,8 \\
\hline De 26 a 40 anos & 25,0 & Masculino & 36,2 \\
\hline De 41 a 60 anos & 34,6 & Total & 100,0 \\
\hline Acima de 60 anos & 9,6 & & \\
\hline Total & 100,0 & & \\
\hline Renda & $\%$ & Escolaridade & $\%$ \\
\hline Até 2 salários mínimos & 2,9 & Ensino fundamental e médio & 24,0 \\
\hline De 2 a 4 salários mínimos & 13,3 & Superior incompleto & 30,8 \\
\hline De 4 a 10 salários mínimos & 46,7 & Superior & 45,2 \\
\hline De 10 a 20 salários mínimos & 25,7 & Total & 100,0 \\
\hline Mais de 20 salários mínimos & 11,4 & & \\
\hline Total & 100,0 & & \\
\hline Estado Civil & $\%$ & Local de Residência & $\%$ \\
\hline Casados & 41,0 & Camobi & 39,0 \\
\hline Solteiros & 52,4 & Centro & 21,0 \\
\hline Viúvos & 3,8 & Outros Bairros & 40,0 \\
\hline Divorciados & 2,9 & Total & 100,0 \\
\hline Total & 100,0 & & \\
\hline Moradores por Residência & $\%$ & Relação com a UFSM & $\%$ \\
\hline Uma pessoa & 15,2 & Estudante & 26,7 \\
\hline Duas pessoas & 20,0 & Servidor - Prof./ TAE & 44,8 \\
\hline Três Pessoas & 31,5 & Prestador de Serviço & 5,7 \\
\hline Quatro pessoas & 18,1 & Comunidade Externa & 19,5 \\
\hline Cinco ou mais & 15,2 & Visitante & 3,5 \\
\hline Total & 100,0 & Total & 100,0 \\
\hline
\end{tabular}

Fonte: dados da pesquisa.

Como se pode observar no quadro, a localização espacial do evento tipifica os entrevistados. Ou seja, por estar localizada em uma área central do campus da UFSM, no bairro Camobi, que fica cerca de quinze quilômetros do Centro de Santa Maria, a ocorrência da feira promove um ponto de encontro do público que hodiernamente convive no ambiente da cidade universitária, seja trabalhando, seja estudando. Dessa forma, todos os números levantados são tendenciados pela questão espacial. Assim, a Polifeira da UFSM promove uma sociabilidade diferenciada, pois no espaço da feira se observa a circulação de muitos jovens, público incomum nesse tipo de evento. Tal constatação torna-se um desafio para os feirantes como ressalta Radomsky e Àvila (2018), pois o empenho para uma comunicação proporciona a criação de valor pela confiabilidade e a confiança mútua em relação a seus produtos. Cabe destacar que este público jovem não é apenas transeunte, mas consumidor, pois perfaz $31 \%$ da amostra'.

${ }^{1}$ A estimativa interna da UFSM é de que há uma circulação diária de 30.000 pessoas no campus. A comunidade universitária é constituída por 1.764 docentes, 2.605 servidores técnicos administrativos em educação e 23.521 acadêmicos em cursos presenciais, sendo 222 cursos em diferentes graus, dos quais 101 são de graduação. Além desse público, têm-se também os usuários do Hospital Universitário, que se localiza no Campus Central (https://portal.ufsm.br/ufsm-em-numeros/público/index.html). 
Outra questão que os resultados revelam é a baixa participação da comunidade externa, pois esses consumidores somam apenas $23 \%$ do total. Tal resultado está ligado ao tempo do projeto, pois a feira possuía apenas seis meses de funcionamento no momento da pesquisa e os moradores da comunidade externa à Universidade ainda estão descobrindo esse espaço de compras. Tal afirmação foi averiguada pela pergunta de como os entrevistados ficaram sabendo da ocorrência da feira. O meio de divulgação mais eficiente foram os amigos, seguidos de panfletos publicitários da feira. Nesta averiguação, como este canal se configura como sendo de mercado local e territorial, uma das garantias para o seu funcionamento, como destaca Schneider (2016), é a reputação. Para o caso, é a percepção dos "amigos" a primeira referência de qualidade e satisfação, e estes é que fazem a indicação para outros consumidores.

Quanto aos hábitos de consumo alimentar, $87,62 \%$ dos consumidores pesquisados são onívoros, 3,81\% veganos e $8,57 \%$ vegetarianos ${ }^{2}$.

Quando questionados sobre restrições alimentares e consumo, 32,38\% dos entrevistados apontaram possuir alguma restrição alimentar, sendo que a mais comum foi a lactose (26\%) e o açúcar (23\%).

Em relação à intenção de compras, $66 \%$ dos entrevistados frequentam a feira para comprar frutas, legumes e verduras, os denominados FLV. Tal constatação parece ser recorrente, pois no estudo de Carvalho, Rezende e Rezende (2010) também foi constatado as FLV como principal intenção de compras. Esses autores apontam que os consumidores, independente da capacidade financeira, relacionam a feira como local propício à obtenção de alimentos que proporcionam uma alimentação saudável, além de ser um ambiente para lazer.

Quanto ao consumo domiciliar de FLV, 57\% dos entrevistados afirmam que este vem crescendo nos últimos anos, 33\% que não houve variação e 10\% que reduziu.

O Gráfico 1 apresenta a frequência de acesso dos consumidores na Polifeira, indicando que cerca de $64 \%$ destes, a frequentam toda semana.

Gráfico 1. Frequência dos consumidores na Polifeira

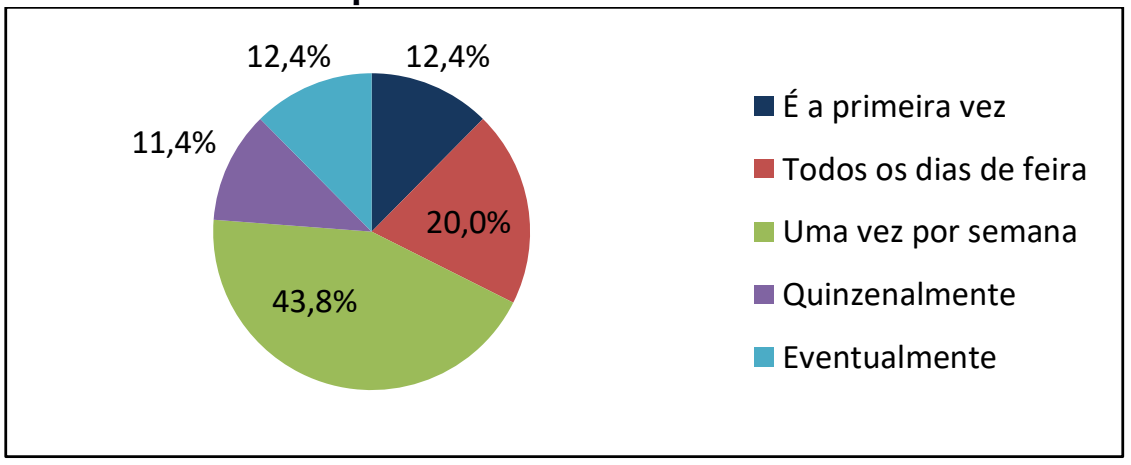

Fonte: dados da pesquisa.

\footnotetext{
${ }^{2}$ Segundo o dicionário Michaelis, onívoro é aquele que se alimenta tanto de substâncias vegetais como animais; vegetariano é aquele que se alimenta só de vegetais (fitófago, herbívoro); vegano é aquele adepto a filosofia de vida e dieta que excluem o uso de qualquer produto de origem animal na alimentação e no vestuário (https://michaelis.uol.com.br).
} 
Cabe salientar que a maioria desses consumidores eventuais estava indo pela primeira vez e afirma ter gostado da feira e que pretende retornar.

Os consumidores foram questionados sobre a média de gasto por feira, cujos resultados são apresentados no Gráfico2.

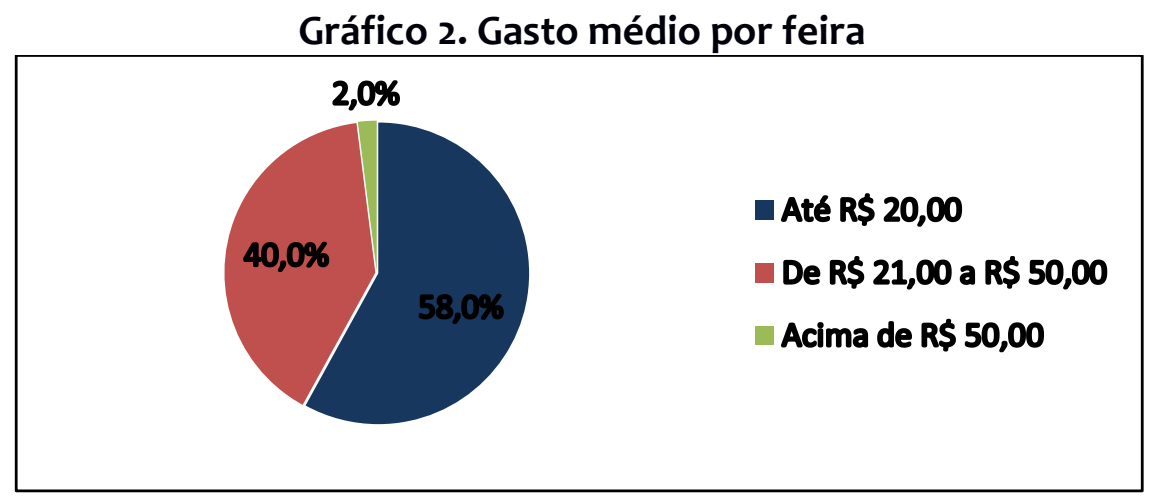

Fonte: dados da pesquisa.

Observando a média de gastos dos consumidores, constata-se que a maioria

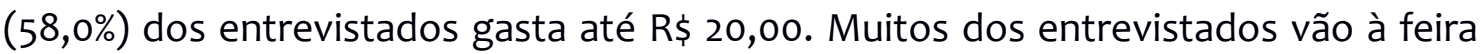
para fazer um lanche rápido ou para comprar somente o necessário em FLV, que não tem um preço elevado. Os maiores valores estão ligados à compra de produtos lácteos e embutidos. Novamente se destaca a importância das FLV como itens mais procurados nas feiras, semelhante ao estudo de Carvalho, Rezende e Rezende (2010).

Para avaliarmos o grau de satisfação dos consumidores quanto a alguns quesitos da Polifeira, foram observadas as percepções dos consumidores quanto a três quesitos: infraestrutura da feira, feirantes e seus produtos. O Gráfico 3 apresenta o grau de satisfação dos consumidores referente ao quesito infraestrutura da feira.

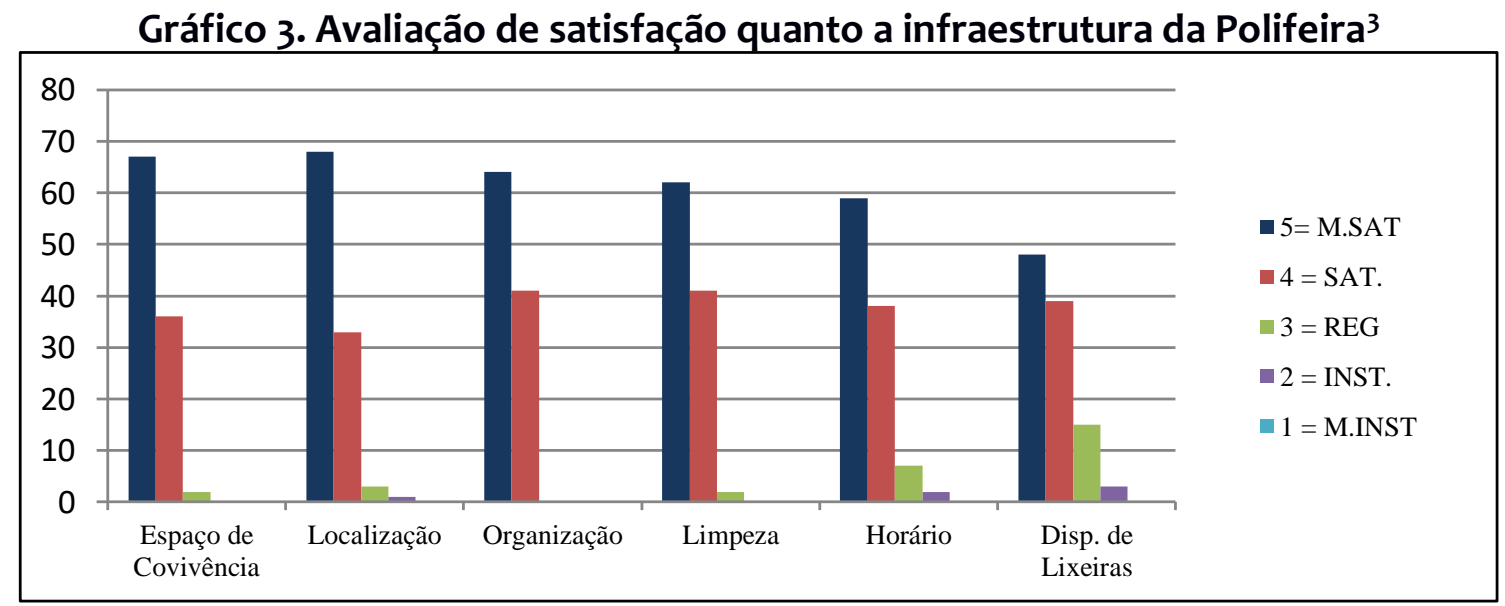

Fonte: dados da pesquisa.

Quase todos os itens associados à infraestrutura ficaram acima da mediana em grau máximo de satisfação. A maior satisfação corresponde à localização da feira

\footnotetext{
${ }^{3}$ Nos gráficos de avaliação 3, 4 e 5 as legendas representam respectivamente: 5 = muito satisfeito; $4=$ satisfeito; 3 = regular; 2 = insatisfeito e 1 = muito insatisfeito.
} 
e o aspecto de menor avaliação foi a disponibilidade de lixeiras, que obteve $18 \%$ de avalições entre regular e insatisfeito.

A satisfação quanto a alguns itens específicos do comportamento e hábitos dos feirantes em relação ao atendimento dos consumidores, pode-se observar no Gráfico 4 que estes cumprem com as expectativas dos consumidores quantos aos quesitos confiança, atendimento e uso de material de proteção e higiene.

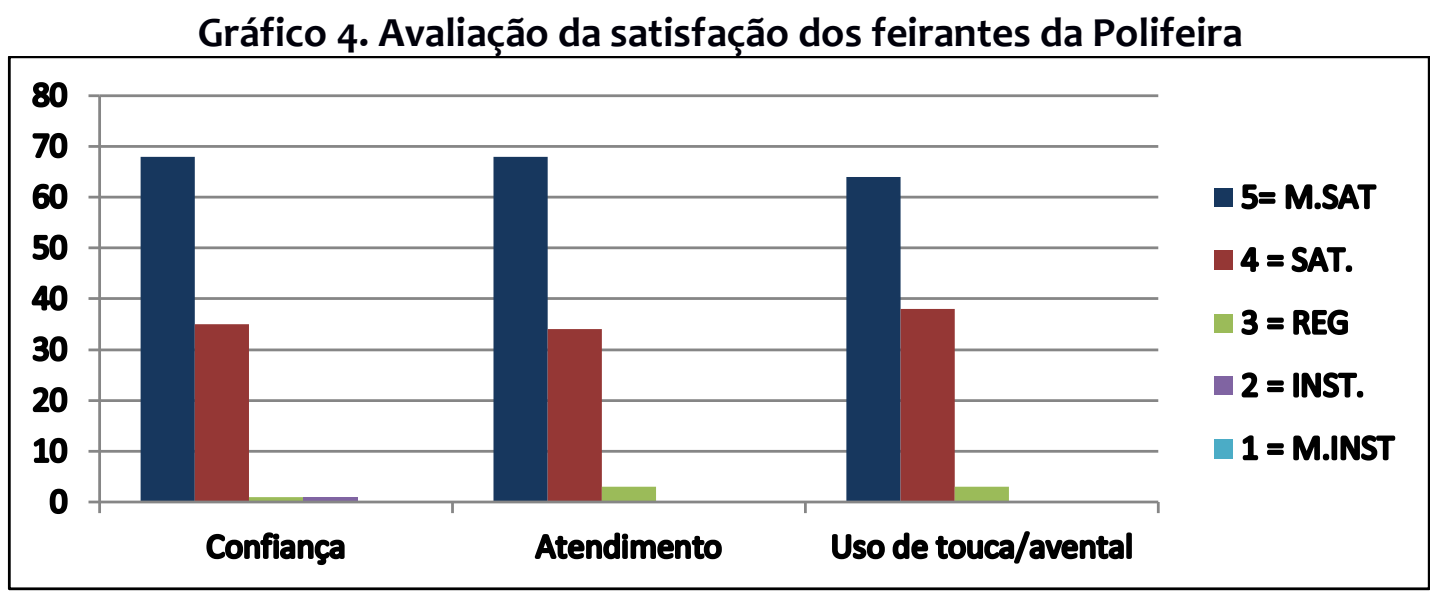

Fonte: dados da pesquisa.

O resultado da avaliação da satisfação dos consumidores quanto aos produtos, está ilustrada no Gráfico 5 , indicando elevada frequência nos pontos "Muito satisfeito" e "Satisfeito". Isso demonstra que os produtos comercializados na Polifeira atendem de forma satisfatória as expectativas dos consumidores. Mesmo os quesitos variedade e preço, em que houve ocorrências de consumidores insatisfeitos e muito insatisfeitos, essas foram pouco expressivas em relação ao quantitativo total de respondentes.

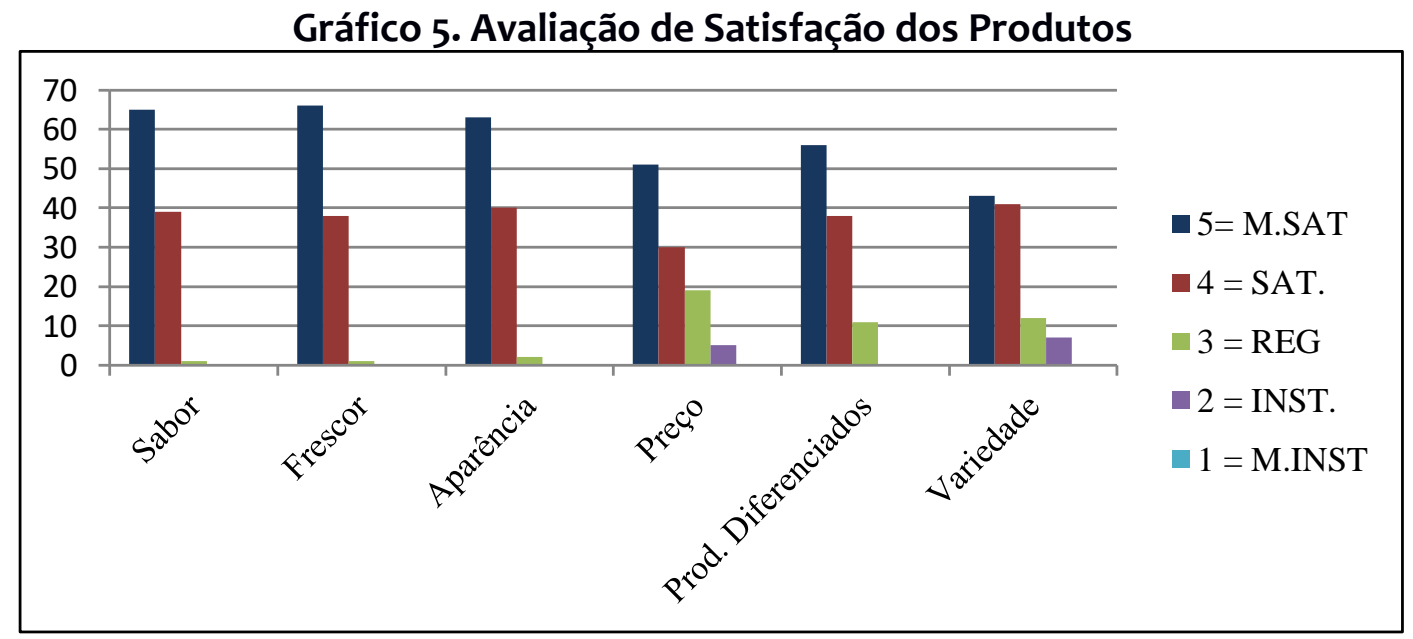

Fonte: dados da pesquisa.

Ao observarmos os resultados da satisfação dos consumidores quanto a infraestrutura, feirantes e produtos percebe-se que para o caso analisado as expectativas estão sendo atendidas de forma positiva em todos os quesitos analisados. Como destaca Salomon (2002), os consumidores ao se sentirem 
satisfeitos podem propiciar a criação de valor que será importante para a fidelização dos consumidores.

A análise descritiva de satisfação apresentada na Tabela 1 corrobora e complementa os resultados apresentados acima. Em todos os quesitos, a satisfação média esteve acima de quatro $(4,00)$, indicando que os consumidores da Polifeira estão, de maneira geral, satisfeitos com a mesma. A maior satisfação está associada à localização, atendimento, frescor dos produtos e confiança, que obtiveram satisfação média de 4,62. O menor grau de satisfação refere-se à variedade de produtos $(4,16)$, seguido do preço dos produtos $(4,21)$ e da disponibilidade de lixeiras $(4,26)$, que foram os quesitos com mediana 4,00 , comparativamente a todos os demais que obtiveram mediana 5,00. A maior variabilidade nas respostas, por um lado, está na satisfação com relação ao preço dos produtos, que obteve um desviopadrão de 0,906. Por outro lado, a maior homogeneidade foi encontrada na avaliação da organização da Polifeira, que registrou um desvio-padrão de 0,490.

\begin{tabular}{|l|c|c|c|c|}
\multicolumn{7}{c}{ Tabela 1. Análise descritiva da satisfação } & \\
\hline & Média & Mediana & Moda & Desvio-padrão \\
\hline Localização & 4,62 & 5,00 & 5 & 0,544 \\
\hline Horário & 4,46 & 5,00 & 5 & 0,707 \\
\hline Organização & 4,61 & 5,00 & 5 & 0,490 \\
\hline Atendimento & 4,62 & 5,00 & 5 & 0,544 \\
\hline Uso touca/avental & 4,58 & 5,00 & 5 & 0,551 \\
\hline Limpeza & 4,57 & 5,00 & 5 & 0,535 \\
\hline Disponibilidade de lixeiras & 4,26 & 4,00 & 5 & 0,809 \\
\hline Espaço de convivência & 4,59 & 5,00 & 5 & 0,631 \\
\hline Variedade de produtos & 4,16 & 4,00 & 4 & 0,878 \\
\hline Frescor dos produtos & 4,62 & 5,00 & 5 & 0,507 \\
\hline Sabor & 4,61 & 5,00 & 5 & 0,509 \\
\hline Aparência e formato do produto & 4,58 & 5,00 & 5 & 0,533 \\
\hline Preço dos produtos & 4,21 & 4,00 & 5 & 0,906 \\
\hline Produtos diferenciados & 4,43 & 5,00 & 5 & 0,677 \\
\hline Confiança & 4,62 & 5,00 & 5 & 0,561 \\
\hline
\end{tabular}

Fonte: dados da pesquisa.

A partir desta análise descritiva mais geral da satisfação dos consumidores da Polifeira, foram realizados alguns cruzamentos entre variáveis de interesse, a fim de observar a influência entre estas.

O cruzamento das variáveis, Relação UFSM e Satisfação demonstrou não haver diferença estatisticamente significativa na satisfação média dos consumidores, independentemente do tipo de vínculo com a Universidade, em relação a todos os quesitos avaliados (localização, horário, organização, atendimento, etc.). Ou seja, a satisfação dos consumidores em relação a esses quesitos não está associada ao vínculo com a UFSM.

Ao avaliar a relação entre o hábito alimentar e o grau de satisfação dos consumidores da Polifeira conclui-se que, para a absoluta maioria dos quesitos avaliados, não há diferença estatisticamente significativa entre a satisfação média dos consumidores onívoros, vegetarianos e veganos. Apenas a avaliação da utilização de touca e avental mostrou-se estatisticamente diferente $(F=3,124 ; p=0,048)$ entre 
os tipos de consumidores, sendo que a satisfação média dos onívoros (4,63) é maior em relação à satisfação média dos vegetarianos $(4,22)$ e veganos $(4,25)$. Esse resultado pode sinalizar para um maior grau de exigência dos consumidores veganos e vegetarianos em relação a este quesito. Contudo, cabe salientar que estes representam apenas cerca de $12 \%$ dos consumidores entrevistados.

Portanto, observando as análises descritivas e alguns cruzamentos pode-se inferir que a Polifeira realizada no campus da UFSM vem atendendo de modo satisfatório as expectativas dos seus distintos consumidores.

\section{Apontamentos Finais}

As feiras livres representam um canal diferenciado de comercialização para o abastecimento de alimentos. Como destaca a literatura, neste tipo de canal de comercialização a criação de valor para os consumidores está ancorada na confiança, reputação e honra. Estes valores são criados no momento da socialização entre feirantes e consumidores. No caso da Polifeira, a confiança, entre estes valores de sociabilidade, teve a avaliação de que atendeu as expectativas dos consumidores influenciando na sua decisão de compra. Contudo cabe salientar que para o caso, a Polifeira por ser um projeto de extensão da Universidade, o empenho dos feirantes e o tutelamento da Universidade proporciona um mix (SCHNEIDER, 2016) para a regulação e funcionamento deste mercado. E este mix acaba configurando as relações de comercialização que estão sendo estabelecidas.

Quanto a análise sobre o perfil e os hábitos alimentares dos consumidores da Polifeira da Universidade Federal de Santa Maria este não traz novidades em termos de importância sobre as funções socioeconômicas da feira livre, nem a busca de produtos, pois as frutas, legumes e verduras são as mais procuradas, a exemplo de outros estudos sobre o tema. O diferencial é o consumo realizado pelo público jovem, que comumente não frequenta os chamados mercados locais e de proximidade. Este tipo de experiência está sendo avaliada como satisfatória e pode estar gerando a criação de valores que irão fidelizar estes consumidores por mais tempo.

A satisfação positiva encontrada nos resultados quanto a infraestrutura, a ação dos feirantes e os seus produtos, demonstram que inciativas como esta podem ajudar na criação de canais alternativos de comercialização para os agricultores familiares. Além disso, um dia de feira na Universidade pode influenciar os jovens a criarem uma relação mais próxima com este canal de comercialização ao vivenciarem como experiência de satisfação a confiabilidade exercitada pela socialização.

\section{REFERÊNCIAS}

BARROS, M. A. B.; LOPES, G. M. B.; WANDERLEY, M. B. Tipologia do consumo de frutas: um estudo sobre o comportamento do consumidor de banana. Revista Produção OnLine, Florianópolis, v. 7, n. 1, p. 1-14, dez. 2007. 
CARVALHO, F. G. REZENDE, E.; G.; REZENDE, M. L. Hábitos de compra dos clientes da Feira Livre de Alfenas-MG. Organizações rurais \& agroindustriais, v. 12, n. 1, 2010. ENGEL, J. F.; BLACKWELL, R. E.; MINIARDI, P. W. Comportamento do consumidor. São Paulo: Pioneira, Thomson Learning, 2005.

FREUND, J. E. Estatística aplicada: economia, administração e contabilidade. 11 ed. Porto Alegre: Bookman, 2006.

GIL, A. C. Como Elaborar Projetos de Pesquisa. 4 ed. São Paulo: Atlas, 2002.

GODOY, W. I.; DOS ANJOS, F. S. A Importância das feiras livres ecológicas: um espaço de trocas e saberes da economia local. Revista Brasileira de Agroecologia, v. 2, n.1, fev. 2007.

MALHOTRA, N. K. Pesquisa em marketing: uma orientação aplicada. 3 ed. Porto Alegre: Bookman, 2001.

PLOEG, J. D. Van Der. Camponeses e impérios alimentares: lutas por autonomia e sustentabilidade na era da globalização. Porto Alegre: Ed. UFRGS, 2008.

KOTLER, P.; ARMSTRONG, G. Princípios de Marketing. 15 ed. São Paulo: Pearson Prentice Hall, 2014.

RADOMSKY, G. F. W.; ÁVILA, M. L. L. Riscos, qualidades e sociabilidades em feiras: a perspectiva de feirantes em dois espaços de comercialização em Porto Alegre, RS. Revista Ciências Sociais em Perspectiva, v. 17, n. 32, p. 80-99, 2018.

RENTING, H.; MARSDEN, T.; BANKS, J. Compreendendo as redes alimentares alternativas: o papel de cadeias curtas de abastecimento de alimentos no desenvolvimento rural. In: GAZOLLA, M.; SCHNEIDER, S. (Org.). Cadeias curtas e redes agroalimentares alternativas: negócios e mercados da agricultura familiar. 1. ed. Porto Alegre: EdUFRGS, 2017.

SALOMON, M. R. O comportamento do consumidor: comprando, possuindo e sendo. 5. ed. Porto Alegre: Bookman, 2002.

SCHNEIDER, S. Mercados e agricultura familiar. In: MARQUES, F.; CONTERATO, M.; SCHNEIDER, S. (Orgs.). Construção de mercados e agricultura familiar: desafios para o desenvolvimento rural. Editora da UFRGS. Série Estudos Rurais, 2016, p. 93.

SILVA, M. L. P.; RODRIGUES, J. M. O discurso do sujeito na feira livre: uma análise dos jogos de verdade nas relações sociais contemporâneas como construções de saberes. In: CONGRESSO LUSO-AFRO-BRASILEIRO DE CIÊNCIAS SOCIAIS, 2011, Salvador. Anais... Salvador, 7-10 ago. 2011 
Suzimary Specht. Licenciada em Geografia. Especialista em Educação Ambiental. Mestre em Geografia. Doutora em Desenvolvimento Rural. Professora Adjunta no Curso de Gestão Ambiental - UFSM. suzimary.specht@ufsm.br

Roni Blume. Bacharel e Licenciado em Geografia. Mestre em Desenvolvimento Rural. Doutor em Agronegócio. Professor associado nos Cursos de Gestão Ambiental, Gestão em Cooperativas, e Agronegócio - UFSM. roni.blume@ufsm.br

Marta Von Ende. Bacharel em Administração. Especialista em Estatística e Modelagem Quantitativa. Mestre e Doutora em Administração. Professora adjunta no Colégio Politécnico da UFSM. Docente colaboradora no Programa de Pós-Graduação em Administração da UFSM (PPGA/UFSM). marta@politecnico.ufsm.br

Mylla Trisha Mello de Souza. Graduanda em Engenharia Florestal - UFSM. Bolsista desde 2017, do projeto de extensão: Polifeira UFSM, do Grupo de Pesquisa GIPAG (Grupo Interdisciplinar de Pesquisas Agroalimentares Georreferenciadas) - UFSM. mylla_trisha@hotmail.com

Como citar: SPECHT, Suzimary et al. É dia de fazer feira na Universidade: análise do perfil do consumidor da Polifeira. Redes, Santa Cruz do Sul, v. 24, n. 3, p. 183-197, set. 2019. ISSN 19826745. Disponível em: https://doi.org/10.17058/redes.v24i3.14124. 